\title{
The Impact of Policy Intervention on Regional Economic Growth in China
}

\author{
Lidan Yu, Shiyu Shang \\ Institute of Industrial Economics, Jinan University, Guangzhou, China \\ Email: 1140297570@qq.com, vinci071011@163.com
}

How to cite this paper: Yu, L.D. and Shang, S.Y. (2018) The Impact of Policy Intervention on Regional Economic Growth in China. Modern Economy, 9, 2224-2232. https://doi.org/10.4236/me.2018.912137

Received: November 16, 2018

Accepted: December 18, 2018

Published: December 21, 2018

Copyright $\odot 2018$ by authors and Scientific Research Publishing Inc. This work is licensed under the Creative Commons Attribution International License (CC BY 4.0).

http://creativecommons.org/licenses/by/4.0/

\begin{abstract}
As a grand policy of realizing the rapid development of the western region and narrowing the income gap between the western region and the eastern and central regions after China's reform and opening up, it is of great practical significance to objectively study its policy effects. This paper uses the data of municipal districts in Chinese cities from 1997 to 2014 in China City Statistical Yearbook to evaluate the policy effect of the western development strategy by using the method of difference-in-difference propensity score matching (PSM-DID). The research results show that the western development policy has not improved the economic growth of the western region, but has negatively affected the economic growth of the western region. In addition, economic growth in the western region may be due to factors such as fixed asset investment, foreign direct investment, and higher education levels, etc. Therefore, the strategic direction of the development of the western region should focus on human capital investment, improve the market economy system, and strengthen exchanges and cooperation between regions in the future.
\end{abstract}

\section{Keywords}

Policy Intervention, Regional Economic Growth, PSM-DID

\section{Introduction}

Since the reform and opening up in 1978, China's economy has been developing rapidly. In the past 40 years, the average growth rate of GDP has exceeded $8 \%{ }^{1}$. However, at the same time of rapid economic development, China's economic development is also facing a series of problems, especially the dilemma faced by the imbalance of economic development in the eastern, central and western re- 
gions. Therefore, in order to narrow the gap between the economic development of the western region and the central and eastern regions and promote the coordinated development of the inter-regional economy, in September 1999, the Fifth Plenary Session of the 14th Communist Party of China Central Committee proposed that the state should implement the western development strategy. The main measures include: increasing fiscal transfer payments and investment in construction funds, prioritizing construction projects, increasing financial credit support, implementing tax incentives, and adjusting prices using price charging mechanisms, etc.

In the past 20 years, with the deepening of the western development policy, the development of the western region has also presented a thriving scene. However, whether the economic development of the western region is benefiting from the grand policy of western development is a topic that many scholars have been arguing over the past few years. This paper studies the impact of western development on the economic growth of the western region by using the method of difference-in-difference propensity score matching (PSM-DID) and using the data of municipal districts in Chinese cities from 1997 to 2014 . Through the research results, it also provides some policy recommendations for how to implement the western development policy in the future, effectively promote the development of the western region, and narrow the gap in economic development in the eastern, central and western regions.

\section{Literature Review}

Up to now, a large number of scholars have conducted a comprehensive and multi-angle evaluation of the policy effects of the Western Development. On the one hand, some scholars believe that the western development policy is not the reason for promoting economic growth in the western region. Ruiming Liu and Renjie Zhao [1] pointed out that the western development strategy had not effectively promoted the rapid growth of GDP and per capita GDP in the western region. There was a "policy trap" in the process of implementing western development strategy. Weiyu Gan et al. [2] found that although western development strategy promoted the overall improvement of the social and economic development indicators in the western region, the systemic pattern of regional economic development imbalance between the eastern and western regions had not changed, but instead deteriorating trend. On the other hand, some scholars have come to the conclusion that the western development had promoted economic growth in the western region. Shenglong Liu et al. [3] found that the implementation of the western development policy had increased the average annual economic growth rate in the western region since 2000 by about 1.5 percentage points, and promoted the China's regional economy from divergence to convergence. Guoping Li et al. [4] discussed the impact of the western development strategy on the quality of economic growth in the western region from the perspectives of macroeconomic productivity, industrial structure optimization and 
upgrading, and enterprise economic benefits. The research found that the western development strategy promoted the improvement of the quality of economic growth in the western region to a certain extent. The policy had basically achieved the strategic goal of "sound and fast development, highlighting the quality and efficiency of economic growth".

Moreover, some other scholars have evaluated the western development policy from other perspectives. Yucai Xiao [5] found that tax incentives played an important role in the development of the western region from the perspective of the preferential tax policy of western development. But because of the multi-faceted problems of preferential policies, the effect of the policy was not obvious. Xi Peng and Zhongchang Chen [6] found that the western development policy had benefited Sichuan, Chongqing, Inner Mongolia and Shaanxi provinces the most, the comprehensive development level had been the most significant, and the development gap with the eastern region was gradually shrinking, while Xinjiang, Yunnan, Guizhou and Guangxi provinces had benefited less. Cheng Zhang et al. [7] considered whether western development policy would bring pollution to the western region. Their research results showed that the western development strategy had not caused the western region to become a pollution refuge, and the pollution-intensive industries in China had experienced regional transfer lag. However, with the deepening of the western development process, the gap of labor output efficiency in the western, central and eastern regions was likely to gradually narrow, resulting in the gradual loss of the pollution shelter.

The above are the different evaluations of some scholars on the western development policy. Regardless of the focus of the debate among scholars, there is a fact that the economic development of the western region has been improved. However, to what extent the improvement is attributed to the western development policy is the concerned issue to be followed in this article.

\section{Data and Method}

\subsection{Data and Variable Descriptions}

The data in this paper come from China City Statistical Yearbook. The time span is from 1997 to 2014. Due to the serious lack of city-level data, this paper uses the data of more than 200 municipal-level cities. Further, due to the lack of data in Tibet and Hainan, this paper does not include data in Tibet and Hainan. Therefore, the western region of this paper includes 11 provinces including Yunnan, Sichuan, Chongqing, Guizhou, Shaanxi, Gansu, Ningxia, Xinjiang, Qinghai, Inner Mongolia and Guangxi. The central region includes Hebei, Shanxi, Jilin, Heilongjiang, Anhui, Henan, Jiangxi, Hubei, and Hunan. The eastern region includes Beijing, Tianjin, Shanghai, Shandong, Jiangsu, Zhejiang, Guangdong, Fujian and Liaoning.

The explained variable of this paper is the logarithm of the regional GDP, which measures the economic growth of the municipal district. Two dummy variables are set, $P$ and $T$ respectively, where $P=1$ indicates that the region has 
implemented western development policy, and $P=0$ indicates that the region has not implemented western development policy; $T=1$ indicates the year after the implementation of the western development. It is 2000-2014 in this paper. And $T=0$ indicates the year before the implementation of the western development. It is 1997-1999 in this paper. Table 1 is the main variables of this paper and their calculation methods.

In order to control the influence of other factors, a series of control variables are selected in this paper. The government plays an important role in the economic development in the transitional period. There is a close relationship between government expenditure and economic growth [8]. Therefore, this paper measures the influence of government on regional economy by the proportion of government expenditure (gov). Investment is an important driving force to promote regional economic growth in China. The level of foreign direct investment (fdi) and the level of fixed assets investment (fai) affect regional economic development. Regional industrialization (industry) and the proportion of tertiary industry (third industry) can test the effect of structural factors on regional economic growth. The number of higher education students per 10,000 people (edu) measures the level of human capital in the region. In addition, a typical feature of China's transitional economy is the long-term sustained high savings rate [9], which will affect the level of social investment and consumption, and show a strong correlation with economic growth [10]. Therefore, this paper uses the regional total savings rate (sav) to measure the effect of regional savings level on economic growth. The descriptive statistical results for each variable are shown in Table 2.

\subsection{Measurement Method}

In order to effectively identify the net effect of the western development, we must eliminate other factors that affect the growth of the western region. Academic circles mostly use Difference in Difference (DID) method to evaluate the performance of Western development [11].

The measurement method used in this paper is the difference-in-difference propensity score matching (PSM-DID), which firstly uses the propensity score matching method (PSM) to find the central and eastern regions with similar economic development in the western region from 1997 to 1999, ensuring that they have similar time development trends, and then uses the difference-in-difference method (DID) to compare whether the development gap between the western, central and eastern region is narrowed. Among them, the model set by the DID method is as follows:

$$
Y_{i t}=\beta_{0}+\beta_{1} P_{i t}+\beta_{2} T_{i t}+\beta_{3} P_{i t} T_{i t}+\beta_{4} Z_{i t}+\delta_{i t}
$$

Among them, $Y$ is the explained variable, indicating the logarithm of the region gdp; $P$ and $T$ respectively indicate whether to implement the western development strategy and before or after the implementation of the western development; $Z$ represents other major control variables, the specific variables and 
Table 1. Main variables and their calculation methods.

\begin{tabular}{|c|c|c|}
\hline variable name & variable meaning & calculation method \\
\hline $\operatorname{lngdp}$ & logarithm of the region gdp & take the logarithm of the region gdp \\
\hline west develop & western development & virtual variable $(0,1)$ \\
\hline gov & government size & $\begin{array}{l}\text { (local finance general budget expenditure/region } \\
\text { gdp) } \times 100\end{array}$ \\
\hline fdi & foreign direct investment & $\begin{array}{l}\text { (the actual amount of foreign investment in the } \\
\text { year/region gdp) } \times 100\end{array}$ \\
\hline fai & fixed asset investment & (fixed asset investment/region gdp) $\times 100$ \\
\hline industry & industrialization level & $\begin{array}{l}\text { the proportion of the second industry in the region } \\
\text { as a percentage of gdp (\%) }\end{array}$ \\
\hline third industry & industrial structure & $\begin{array}{l}\text { the proportion of the tertiary industry in the region } \\
\text { as a percentage of gdp }(\%)\end{array}$ \\
\hline edu & education level & $\begin{array}{l}\text { [population in regular higher education } \\
\text { institutions/(regional total population at the } \\
\text { end of the year } \times 10000)] \times 100\end{array}$ \\
\hline sav & savings rate & $\begin{array}{l}\text { (year-end balance of urban and rural residents' } \\
\text { savings/region gdp) } \times 100\end{array}$ \\
\hline
\end{tabular}

Table 2. Descriptive statistics of main variables.

\begin{tabular}{cccccc}
\hline variable name & Obs & Mean & Max & Min & Std. Dev. \\
\hline lngdp & 4894 & 14.538 & 19.267 & 10.878 & 1.313 \\
west develop & 4931 & 0.278 & 1.000 & 0.000 & 0.448 \\
gov & 4890 & 13.369 & 924.103 & 0.000 & 18.214 \\
fdi & 4493 & 0.531 & 72.722 & 0.000 & 2.028 \\
fai & 4816 & 57.658 & 3758.353 & 0.000 & 74.208 \\
industry & 4827 & 50.539 & 92.300 & 8.050 & 12.513 \\
third industry & 4826 & 41.358 & 85.950 & 5.080 & 10.698 \\
edu & 4641 & 3.624 & 29.159 & 0.000 & 3.807 \\
sav & 4870 & 91.179 & 4561.767 & 0.000 & 110.978 \\
\hline
\end{tabular}

Data sources: China City Statistical Yearbook from 1997-2014.

their meanings are shown in Table $1 . \delta$ represents the random error term, assuming it follows a normal distribution. The subscripts $i$ and $t$ represent the $i$-th prefecture-level city and the $t$-th year, respectively. $\beta_{3}$ is the main parameter of this article. If $\beta_{3}>0$, it means that the western development policy has indeed promoted the development of the western region; If $\beta_{3}<0$, it means that the western development policy has not promoted the economic development of the western region.

\section{Empirical Results and Robustness Test}

\subsection{Empirical Analysis}

As mentioned above, this paper uses the DID method to test the impact of the 
western development on the economic growth in the western region. The results are shown in Table 3. The column (1) is the result of not adding the control variable, and the column (2) is the result after adding other control variables. From the result of column (1), it can be seen that the western development policy has not only promoted the development of the western region, but also significantly slowed the economic growth of the western region. With the development of time, the economy of the western region has grown significantly. From this result, it can be explained that the western development is not the reason for promoting economic growth in the western region. The main factors for economic growth in the western region may be derived from the external environment, such as national economic growth brought about by reform and opening up, China's accession to the WTO, and more and more open domestic and international trade environment.

After adding a series of control variables, the result of column (2) shows the western development has a negative effect on the economic growth of the western region. However, the result at this time is no longer significant, further indicating that the western development strategy may not promote the economic development of the western region. Other factors, such as foreign direct investment, education level, fixed asset investment, industrialization level, and industrial structure, etc. have a positive effect, while savings rate has a significant negative impact on economic growth in the western region. This shows that in the development of the western region, the external driving forces, such as foreign direct investment and fixed asset investment, etc. are still important factors driving economic development. Moreover, Technology is the first driving force for development, which also reflects why education has played a key role in promoting the development of the western region. The higher the proportion of the second and third industries is, the higher the level of industrial structure optimization in this area. The optimization and upgrading of the industry will inevitably lead to further economic development. Finally, a high savings rate indicates that people are unwilling to consume, which may not be conducive to regional economic growth, so the savings rate and economic growth show a reverse relationship.

\subsection{Robustness Test}

In order to reduce the bias of the empirical results, this paper further uses the method of difference-in-difference propensity score matching (PSM-DID) for robustness test. Firstly, the tendency scores are obtained by performing logit regression on the control variables by whether implement the western development or not. Then use Kernel Matching to make estimates and test the robustness of the role of the western development in promoting economic development in the western region. The results are shown in Table 4 and Table 5.

It can be seen from the results in Table 4 that the foreign direct investment fdi, the fixed asset investment fai and the industrialization level industry have a significant effect on the explained variable west develop. The negative effect of 
Table 3. The impact of policy intervention on regional economic growth.

\begin{tabular}{|c|c|c|}
\hline variable name & (1) & (2) \\
\hline \multirow[t]{2}{*}{$\mathrm{T}$} & $1.138^{* * *}$ & $0.683^{\star * *}$ \\
\hline & $(22.670)$ & $(13.880)$ \\
\hline \multirow[t]{2}{*}{$P$} & $-0.324^{\star * *}$ & -0.005 \\
\hline & $(-3.550)$ & $(-0.050)$ \\
\hline \multirow[t]{2}{*}{$\mathrm{T}^{\star} \mathrm{P}$} & $-0.301^{* * *}$ & -0.140 \\
\hline & $(-3.000)$ & $(-1.500)$ \\
\hline \multirow[t]{2}{*}{ fdi } & & $0.132^{\star \star \star}$ \\
\hline & & $(3.600)$ \\
\hline \multirow[t]{2}{*}{ edu } & & $0.109^{* * *}$ \\
\hline & & $(20.570)$ \\
\hline \multirow[t]{2}{*}{ fai } & & $0.004^{\star * *}$ \\
\hline & & $(6.020)$ \\
\hline \multirow[t]{2}{*}{ gov } & & -0.004 \\
\hline & & $(-1.140)$ \\
\hline \multirow[t]{2}{*}{ sav } & & $-0.005^{\star * *}$ \\
\hline & & $(-8.320)$ \\
\hline \multirow[t]{2}{*}{ industry } & & $0.053^{* * *}$ \\
\hline & & $(23.560)$ \\
\hline \multirow[t]{2}{*}{ third industry } & & $0.053^{\star * *}$ \\
\hline & & $(15.910)$ \\
\hline \multirow[t]{2}{*}{ _cons } & $13.718^{* * *}$ & $9.006^{* * *}$ \\
\hline & $(309.580)$ & $(39.300)$ \\
\hline $\mathrm{N}$ & 4888 & 4214 \\
\hline $\mathrm{R}^{2}$ & 0.113 & 0.408 \\
\hline
\end{tabular}

Note: ${ }^{*},{ }^{* *},{ }^{* *}$ respectively denote significance at the $10 \%, 5 \%$ and $1 \%$ level.

Table 4. Test results by logit Method.

\begin{tabular}{cc}
\hline variable name & west develop \\
\hline gov & -0.040 \\
fdi & $(-1.180)$ \\
& $-1.811^{* * *}$ \\
fai & $(-4.680)$ \\
& $0.011^{* *}$ \\
industry & $(-2.320)$ \\
& $-0.032^{* *}$ \\
third industry & $(-2.530)$ \\
& -0.023 \\
edu & $(-1.380)$ \\
& -0.120 \\
sav & $(-0.300)$ \\
& 0.002 \\
cons & $(0.500)$ \\
& 1.587 \\
$\mathrm{~N}$ & $(1.360)$ \\
$\mathrm{R}^{2}$ & 654 \\
\hline
\end{tabular}

Note: ${ }^{*},{ }^{* *},{ }^{* *}$ respectively denote significance at the $10 \%, 5 \%$ and $1 \%$ level. 
Table 5. Does western development promote regional economic development: PSM-DID Robustness test.

\begin{tabular}{|c|c|c|c|c|c|c|c|}
\hline & $\begin{array}{l}\text { control group } \\
\text { before western } \\
\text { development }\end{array}$ & $\begin{array}{c}\text { experimental } \\
\text { group before } \\
\text { western } \\
\text { development }\end{array}$ & $\begin{array}{l}\text { difference between } \\
\text { control group and } \\
\text { experimental group } \\
\text { before western } \\
\text { development }\end{array}$ & $\begin{array}{l}\text { control group } \\
\text { after western } \\
\text { development }\end{array}$ & $\begin{array}{l}\text { experimental } \\
\text { group after } \\
\text { western } \\
\text { development }\end{array}$ & $\begin{array}{l}\text { difference between } \\
\text { control group and } \\
\text { experimental group after } \\
\text { western development }\end{array}$ & $\begin{array}{l}\text { test result of } \\
\text { difference-in- } \\
\text { difference }\end{array}$ \\
\hline lngdp & 13.652 & 13.471 & -0.181 & 14.723 & 14.232 & -0.491 & -0.310 \\
\hline sem & & & 0.110 & & & 0.045 & 0.118 \\
\hline value of $t$ & & & -1.660 & & & -11.000 & -2.620 \\
\hline$P>|t|$ & & & $0.098^{*}$ & & & $0.000^{* * *}$ & $0.009^{* * *}$ \\
\hline
\end{tabular}

Note: 1$)^{*},{ }^{* *},{ }^{* *}$ respectively denote significance at the $10 \%, 5 \%$ and $1 \%$ level. 2 ) The number of samples participating in the match is 3796 , of which the number of samples in the experimental group is 129,1216 , and the number of samples in the control group is 405,2046 respectively. 3) The value of $\mathrm{R}^{2}$ is 0.08 .

the foreign direct investment fdi and the industrialization level industry on whether to carry out the western development shows that the reason why the western development is carried out is indeed because the western region is economically backward. Therefore, it is necessary to use the propensity score matching method (PSM) to first match.

The robustness test results in Table 5 show that after using the method of difference-in-difference propensity score matching (PSM-DID) for testing, the test result of difference-in-difference is -0.310 , and the result is significant at the $1 \%$ level, indicating that the policy of western development hasn't had a positive impact on economic growth in the western region, and even has a negative impact on the growth of regional gdp. The robustness test results are consistent with the empirical results we obtained earlier.

\section{Conclusions and Suggestions}

In order to study whether policy intervention promotes the growth of regional economy, this paper uses the data of municipal districts in Chinese cities from 1997 to 2014 in China City Statistical Yearbook to assess the policy effect of western development strategy through the method of difference-in-difference propensity score matching (PSM-DID). The results show that the western development policy has not improved the economic growth, but has negatively affected the economic growth of the western region. The economic growth in the western region may be due to factors such as fixed asset investment, foreign direct investment and education, etc.

Based on the above conclusions, the policy recommendations of this paper are as follows: 1) When the western development strategy strengthens investment in fixed assets, it also needs to strengthen investment in intangible capital represented by human capital. The return on investment in human capital, social resources, and intangible capital is much higher than the return on investment in natural resource development, physical capital, and tangible capital. 2) Improve the market economy system, realize the flow of all-round production factors, improve the market competition mechanism that encourages the survival of 
the fittest, and change the micro-subject structure in the western region. 3) The energy industry in the western region has problems of over-exploitation of resources and a single industrial structure. In the follow-up planning of western development, efforts should be made to develop industries related to the energy industry. 4) In the past, the main driving force for economic development in the western region was the investment driven by the central government's fiscal revenue. In order to realize the leap-forward development of the western region itself, it is necessary to change the economic growth model and increase the synergy and integration among the regions.

\section{Conflicts of Interest}

The authors declare no conflicts of interest regarding the publication of this paper.

\section{References}

[1] Liu, R.M. and Zhao, R.J. (2015) Western Development: Growth Drive or Policy Trap-An Analysis Based on PSM-DID Method. China Industrial Economics, 6, $32-43$.

[2] Gan, W.Y., Xu, X.X. and Yi, J. (2011) Achievement, Problems and Countermeasures for Implementation of Western Development Strategy. Economic Geography, 1, 40-46.

[3] Liu, S.L., Wang, Y.H. and Hu, A.G. (2009) The Effect of Western Development Program and Regional Economic Convergence in China. Economic Research Journal, 9, 94-105.

[4] Li, G.P., Peng, S.Q., Zeng, X.F. and Yang, Y. (2011) Evaluating the Economic Effect of Western China Development Strategy-Based on Economic Growth Quality Perspective. Modern Economic Science, 4, 110-124.

[5] Xiao, Y.C. (2012) The Effect of Tax Preferential Policy and Its Future Direction in Western Development. Finance \& Economics, 3, 85-92.

[6] Peng, X. and Chen, Z.C. (2016) Impact Evaluation on China's Western Development Policy. China Population, Resources and Environment, 3, 136-144.

[7] Zhang, C., Zhou, B., Lv, M.Y. and Liu, X.F. (2017) Has West China Development Directly or Indirectly Brought Pollution Haven? China Population, Resources and Environment, 4, 95-101.

[8] Yang, Z.H. (2011) Nonlinear Study on the Relation between Government Scale, Government Expenditure Growth and Economic Growth. Quantitative Economic and Technological Economic Research, 28, 77-92.

[9] Li, Y. and Yin, J.F. (2005) High Savings, High Investment and China's Economic Growth in the Process of Labor Transfer. Economic Research, 2, 4-15+25.

[10] Wang, W. (2008) Research on Dynamic Correlation between Savings, Investment and Economic Growth-Based on Data Analysis of China from 1952 to 2006. Nankai Economic Research, 2, 105-125.

[11] Mao, Q.L. (2011) Does the Great Development of the West Help to Reduce the Income Inequality in the Western Region-Empirical Study Based on Double Difference Method. Financial Science, 9, 94-103. 